\title{
Health and Behavior
}

National Cancer Institute

\section{Source}

National Cancer Institute. Health and Behavior. NCI Thesaurus. Code C16226.

Research into the combination of knowledge, practices, and attitudes that motivate the actions we take regarding health. 